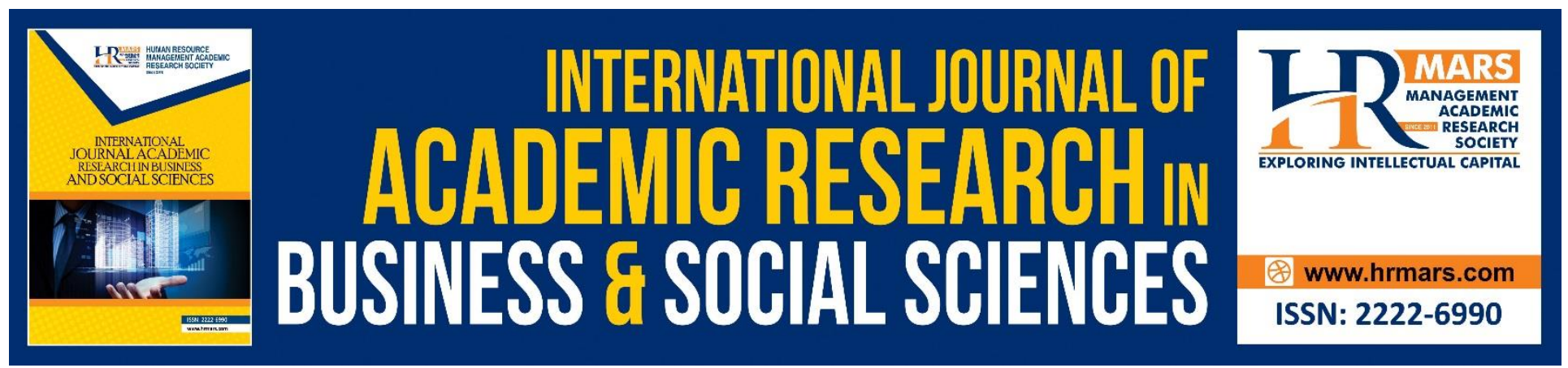

\title{
Correlation Analysis of Occupational Stress and Job Performance in Lebanon
}

\author{
Ahmad Azan Ridzuan, Azman Ismail, Noor Azmi Mohd Zainol \& Suzana Ali \\ Hassan@ Ali
}

To Link this Article: http://dx.doi.org/10.6007/IJARBSS/v8-i6/4313

DOI: $\quad 10.6007 /$ IJARBSS/v8-i6/4313

Received: 24 May 2018, Revised: 19 June 2018, Accepted: 29 June 2018

Published Online: 08 July 2018

In-Text Citation: (Ridzuan, Ismail, Zainol, \& Ali, 2018)

To Cite this Article: Ridzuan, A. A., Ismail, A., Zainol, N. A. M., \& Ali, S. A. H. @. (2018). Correlation Analysis of Occupational Stress and Job Performance in Lebanon. International Journal of Academic Research in Business and Social Sciences, 8(6), 1195-1206.

\section{Copyright: (C) 2018 The Author(s)}

Published by Human Resource Management Academic Research Society (www.hrmars.com)

This article is published under the Creative Commons Attribution (CC BY 4.0) license. Anyone may reproduce, distribute, translate and create derivative works of this article (for both commercial and non-commercial purposes), subject to full attribution to the original publication and authors. The full terms of this license may be seen at: http://creativecommons.org/licences/by/4.0/legalcode

\begin{tabular}{|l|l|}
\hline \multicolumn{2}{|c|}{ Vol. 8, No. 6, June 2018, Pg. 1195 - 1206} \\
\hline http://hrmars.com/index.php/pages/detail/IJARBSS & JOURNAL HOMEPAGE \\
\hline
\end{tabular}

Full Terms \& Conditions of access and use can be found at http://hrmars.com/index.php/pages/detail/publication-ethics 


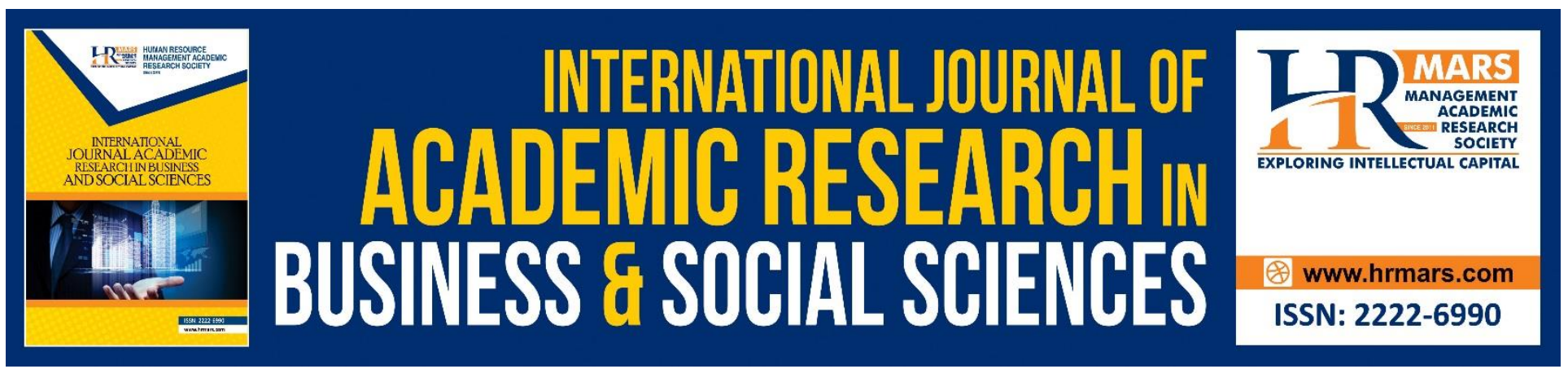

\title{
Correlation Analysis of Occupational Stress and Job Performance in Lebanon
}

\author{
Ahmad Azan Ridzuan', Azman Ismail2, Noor Azmi Mohd Zainol' \& \\ Suzana Ali Hassan @ Ali ${ }^{1}$ \\ ${ }^{1}$ National Defence University of Malaysia. \\ Sungai Besi Camp, 57000 Kuala Lumpur \\ ${ }^{2}$ Faculty of Economics \& Management \\ Universiti Kebangsaan Malaysia, 43600 Bangi, Selangor
}

\begin{abstract}
The purpose of this study was to examine the relationship between occupational stress and job performance by using self-administered questionnaires collected from Malaysian defense and security personnel involved in humanitarian aid in the Middle East. The results of the SmartPLS path model analysis show two important findings: (1) physiological pressure is associated with job performance and (2) psychological stress is associated with significant job performance. These results indicated that occupational stress in humanitarian aid does act as an important determinant in the performance of work in the organization's sample. Furthermore, discussions, implications and conclusions are explained.
\end{abstract}

Keywords: Physiological Stress, Psychological Stress, Job Performance, Humanitarian Assistance

\section{Introduction}

When disaster strikes, the UN and its agencies rush to deliver humanitarian assistance (UN, 2008). Humanitarian assistance includes the material and logistical provision and distribution of aid for people that are in acute humanitarian emergency situations due to natural disasters such as floods in Pakistan in 2010, epidemics of cholera in Haiti in 2010 and also conflicts in Afghanistan (Major 2012). Although humanitarian assistance are frequently associated with lower stressor intensity than combat situations, humanitarian workers are still subjected to stressful situations. United Nations personnel and other humanitarian workers in the field continue to be subject to attacks. Over the years, scores have been killed, taken hostage or detained while working in conflict areas. Violent incidents against UN staff have included armed robbery, assault and rape (UN, 2008). Stress comes from any situation or circumstance that require behavioral adjustment any change either good or bad is stressful or whether it's positive or negative change, the physiological response is same (Colligan \& Higgins, 2010). 
INTERNATIONAL JOURNAL OF ACADEMIC RESEARCH IN BUSINESS AND SOCIAL SCIENCES Vol. 8, No. 6, June 2018, E-ISSN: 2222-6990 @ 2018 HRMARS

Stress is dynamic state whereby the masses are faced with an opportunity, obstacle, constraints or demand regarding what one desires and the implication of which is considered to be uncertain, negative, terrifying and important. (Robbins, 2004). It often occurs when individuals' physical and emotional do not match or cannot handle their job demands, constraints and/or opportunities (Leka et al., 2004; Ugoji, 2003; Ugoji \& Isele, 2009). Stress is a multidimensional construct and may be interpreted based on two major perspectives: eustress and distress conditions (Selye, 1964; Selye, 1987; Ismail et al., 2010). In an organizational context, eustress is often called as positive stress where individuals who have adequate knowledge, skills, abilities and attitudes to cope with their work demands and pressures (Keshavarz \& Mohammadi, 2011; Yu-Fei et al., 2012; Code \& Langan-Fox, 2001; Gachter et al., 2011). On the other hand, distress is also known as negative stress where individuals have not adequate knowledge, skills, abilities and attitudes to cope with external forces and challenges placed on their bodies (Ismail et al., 2010; Keshavarz \& Mohammadi, 2011; Basowitz et al., 1995).

The occupational stress is the by-product of complex industrial organization where stress is excessive, personal and organizational performance is at best damaged (Kwatra et al., 2012). Occupational stress produces negative consequences for workers, such as high health care costs (Goetzel et al., 1998) and increased risk for depression and anxiety (Corpley et al.,1999). Occupational stress refers to individuals who have experienced physiological stress (PHS) and/or psychological stresses (PSS) in carrying out duties and responsibilities to achieve their key performance indicators (Ismail et al., 2010; Ismail et al., 2009; Santos et al., 2010). PHS is normally viewed as a physiological reaction of the body (e.g., headache, migraine, abdominal pain, lethargic, backache, chest pain, fatigue, heart palpitation, sleep disturbance and muscle ache) to various stressful triggers at the workplace that directly and negatively affects an individual's productivity, effectiveness, quality of work and personal health (Ismail et al., 2009; Santos et al., 2010; WHO, 2005). Beehr et al., (2000) found the relationship between occupational stressors and the performance of employees of an organization as well as it can affect the employees psychologically.

While, PSS is often seen as an emotional reaction experienced by an individual (such as anxiety and depression burnout, job alienation, hostility, depression, tension, anger, nervousness, irritability and frustration) as a result from the stimulate at the workplace (Code \& Langan-Fox, 2001; Ismail et al., 2009; Santos et al., 2010; Millward, 2005). Lazarus and Folkman (1984) defined psychological stress as a particular relationship between the person and the environment that is appraised by the person as taxing or exceeding his or her resources and endangering his or her well-being.

Interestingly, extant studies in the workplace stress show that the levels of PHS and PSS may have a significant impact on individual outcomes, especially job performance (JOP) (Ismail et al., 2009; Hsieh, 2004). According to many scholars, JOP can be viewed as an activity in which an individual is able to accomplish successfully the task assigned to him or her, subject to the normal constraints of the reasonable utilization of available resources (Jamal, 1984). JOP is usually defined as the ability of individuals to accomplish their respective work goals, meet their expectations, achieve benchmarks or attain their organizational goals (Campbell, 1990; Bohlander et al., 2001). In an occupational stress model, several scholars believe that the ability of employees to properly identify, regulate and manage their PHS and PSS in executing job may lead to higher JOP in organizations (Millward, 2005; Hourani, 2006). 
INTERNATIONAL JOURNAL OF ACADEMIC RESEARCH IN BUSINESS AND SOCIAL SCIENCES Vol. 8, No. 6, June 2018, E-ISSN: 2222-6990 @ 2018 HRMARS

In terms of broad behavioural construct, the general taxonomy of job performance includes "assessment of performance, analysis of job, and method of job elements" (Dokotri, 2006). Employee's efficiency is reported in terms of one's performance at workplace. Job performance is the individual productivity in both quantitative and qualitative aspects of the job. It shows that how well a person is doing his job and the extent to which the employee is meeting the job duties and the policies and standards of his organization while doing his job. Job performance depends upon the atmosphere of office, work settings and the social interactions (Coetzer \& Rothmann, 2006).

Within an organizational stress model, many scholars concur that PHS, PSS and JOP are distinct, but strongly interconnected concepts. For example, the capability of employees to properly manage their PHS and PSS in executing job may lead to an enhanced JOP in organizations (Ismail et al., 2009; Johnston, 2013; Nabirye et al., 2011). Although the nature of this relationship is interesting, the role of occupational stress as an important determinant is inadequately explained in the workplace stress models (Slaski \& Cartwright, 2002; Slaski \& Cartwright, 2003). Many scholars argue that the role of occupational stress as an important determinant is not adequately explained in the previous studies because they have much emphasized on debating occupational stress concept, employed a metaanalysis method to describe the features of occupational stress in various organizational settings, implemented a simple survey method to assess respondent attitudes toward occupational stress features, and neglected to measure the effect size and nature of the correlation between occupational stress and job performance. As a result, this study paradigm has provided inadequate findings to be used as important recommendations by practitioners in understanding the complexity of occupational stress and formulating occupational stress programs for growth and competitive organizations (Johnston, 2013; Slaski \& Cartwright, 2002; Slaski \& Cartwright, 2003). Thus, it encourages the researchers to further discover the nature of this relationship.

\section{Purpose Of The Study}

This study has two fold objectives: first, is to examine the relationship between physiological stress and job performance. Second, is to examine the relationship between psychological stress and job performance.

\section{Literature Review}

The influence of occupational stress on individual outcomes is consistent with the notion of occupational stress theory. For example, Karasek and Theorell's (1990) job strain model explains that level of job demands is higher than level of job control may reinforce high risk of individuals' physiological and psychological stresses. Besides that, Edward's (1998) P-E fit theory (Edwards, 1998) suggests level of job demands is higher than available resources may induce two forms of strains, that is physiology (e.g., raised blood pressure and lowered immunity) and psychology (e.g., sleep disturbances, anxiety, panic attacks, and restlessness). Lazarus's (1995) transaction theory suggests that the individual's appriasal of the stressor and the coping strategy used by the individual to buffer the relation between stress and strain (focuses on individual patterns of response to various working conditions in order to understand stress in workplace). According to social role theory explained by Davis (1996), every employee holds various roles that are defined by the organizational culture or by the subculture of a particular group where the expectations are relevant to the job performance. 
INTERNATIONAL JOURNAL OF ACADEMIC RESEARCH IN BUSINESS AND SOCIAL SCIENCES

Vol. 8, No. 6, June 2018, E-ISSN: 2222-6990 @ 2018 HRMARS

The notion of these theories has gained strong support from the workplace stress research literature. For example, several recent studies using a direct effect model were conducted to investigate occupational stress based on different samples like 254 nurses over three nursing shifts (Johnston, 2013), 333 nurses from four hospitals in Kampala, Uganda (Nabirye et al., 2011), 304 call center employees in the UK (Slaski \& Cartwright, 2002), 100 nurses from a large general teaching hospital in Scotland (Morrison et al., 2013), and 213 employees at six geographic Logistics Centers within a medium-sized Fortune 500 company in the Southeastern United States (Cincotta, 2005). The outcomes of these studies reported that high levels of physiological and psychological stresses had decreased the ability of employees in planning and managing their job needs and expectations. As a result, it could lead to lower job performance in the respective organizations (Johnston, 2013; Nabirye et al., 2011; Slaski \& Cartwright, 2002; Morrison et al., 2013; Cincotta, 2005). Based the literature, it was hypothesized that:

$\mathrm{H} 1$ : There is a significant relationship between level of physiological stress and job performance.

$\mathrm{H} 2$ : There is a significant relationship between level of psychological stress and job performance.

\section{Methodology}

This study employed a cross-sectional research design because it allowed the researchers to integrate the occupational stress research literature, the semi-structured interview and the actual survey as a main procedure to collect data for this study. This research design is beneficial to help the researchers in collecting accurate data, less bias data and high quality data (Cresswell, 1998; Sekaran \& Bougie, 2011). This study involved defence and security personnel who are supervised by Malaysian Defence and Security Agency (MDSA) in order to achieve the humanitarian assistance of the United Nation at a Middle Eastern country. At the initial stage of data collection, a survey questionnaire was drafted based on the occupational stress literature. Next, the semi structured interview was conducted involving four experienced defence and security personnel officers comprising of the head of delegation, a senior officer, an administrative officer and a logistic staff officer who had the relevant experience in humanitarian assistances. The information gathered from this interview method was used to understand the nature and characteristics of occupational stress and job performance, as well as the relationship between such variables in the context of this study. After that, the pilot study was conducted by discussing the survey questionnaire with the interviewed participants to verify the content and format of the questionnaire for an actual study. Hence, a back translation technique was employed to translate the content of survey questionnaire into Malay and English versions in order to enhance the validity and reliability of research findings (Cresswell, 1998; Sekaran \& Bougie, 2011).

The survey questionnaire has two major sections: first, physiological stress had 16 items and psychological stress had 3 items that were adapted from occupational stress literature (Slaski \& Cartwright, 2002; Morrison et al., 2013; Beehr et al., 2001). The dimensions used to measure physiological stress are symptoms of physical sickness. While, the dimensions used to measure psychological stress are symptoms of emotional and mental sicknesses. Finally, job performance had 4 items that were adapted from job performance literature (Hsieh et al., 2004; Morrison et al., 2013; AbuAIRub, 2004). The dimensions used to measure job performance are self-development and improvement, sense of accomplishment, self-confidence and pay increase, All items used in the questionnaires were measured using a 7-item scale ranging from "strongly never/strongly disagree" 
INTERNATIONAL JOURNAL OF ACADEMIC RESEARCH IN BUSINESS AND SOCIAL SCIENCES Vol. 8, No. 6, June 2018, E-ISSN: 2222-6990 @ 2018 HRMARS

(1) to "strongly always/strongly agree" (5). Demographic variables were used as controlling variables because this study focused on government personnel attitudes.

A convenient sampling technique was employed to distribute 400 self-administered questionnaires to Malaysian defence and security personnel who involved in the humanitarian assistance operations. This sampling technique was employed because the list of registered defence and security personnel was not given to the researchers for confidential reasons and this condition did not allow the researchers to randomly select participants in the organization. Of the number, 142 useable questionnaires were returned to the researchers, yielding a 35.5 percent response rate. The survey questionnaires were answered by participants based on their consents and a voluntarily basis. This figure meets a good decision model as suggested by Krecjcie and Morgan (1970), and exceeds the minimum sample of probability sampling, showing that it can be analyzed using inferential statistics (Sekaran \& Bougie, 2011). Further, the SmartPLS 3.0 as recommended by Hair et.al (2017), Henseler et al. (2009), and Ringle et al. (2009) to employ assess the psychometric of survey questionnaire data and test the research hypotheses.

\section{Results}

In terms of sample profile, the majority respondent characteristics were males (96.5\%), aged between 21 and 30 years old (74\%), many of them were from low rank officers $(66.9 \%)$, many of them were SPM/MCE holders (66.2\%), their length of service ranged from 6 to 10 years (35.9\%), and a majority of the defence and security personnel were serving with the humanitarian assistance for the first time (95.1\%).

Table 2 shows that physiological stress (PHS), psychological stress (PSS), and job performance (JOP) had the values of average variance extracted (AVE) larger than 0.5 , indicating that they met the acceptable standard of convergent validity (Henseler et al., 2009; Barclay et al., 1995; Fornell \& Larker, 1981). Besides that, all constructs which had the diagonal values of $V$ AVE were greater than the squared correlation with other constructs in off diagonal, showing that all constructs met the acceptable standard of discriminant validity (Henseler et al., 2009).

Table 2: The Results of Convergent and Discriminant Validity Analyses

\begin{tabular}{|l|l|l|l|l|}
\hline Construct & AVE & PHS & PSS & JOP \\
\hline PHS & 0.7490 & $\mathbf{0 . 8 6 5 4}$ & & \\
\hline PSS & 0.6875 & -0.0000 & $\mathbf{0 . 8 2 9 2}$ & \\
\hline JOP & 0.8174 & -0.2345 & 0.4320 & $\mathbf{0 . 9 0 4 1}$ \\
\hline
\end{tabular}

Table 3 shows that the correlation between items and factors for the different constructs, and the construct reliability analysis. The variables loaded more strongly on their own constructs in the model, exceeding the specified minimum, 0.7, showing that the validity of measurement model met the criteria (Fornell \& Larker, 1981; Chin, 1998; Gefen \& Straub, 2005). Besides that, the composite reliability (CR) and Cronbach's Alpha (CA) had values greater than 0.8 , indicating that the instrument used in this study maintained high internal consistency (Henseler et al., 2009; Nunally \& Bernstein, 2006). 
INTERNATIONAL JOURNAL OF ACADEMIC RESEARCH IN BUSINESS AND SOCIAL SCIENCES Vol. 8, No. 6, June 2018, E-ISSN: 2222-6990 @ 2018 HRMARS

Table 3: The Results of Factor Loadings and Cross Loadings for Different Constructs and Construct Reliability Analysis

\begin{tabular}{|l|c|c|c|}
\hline VARIABLE & FL & CR & CA \\
\hline PHS & $0.745-0.931$ & 0.979 & 0.977 \\
\hline PSS & $0.748-0.922$ & 0.868 & 0.813 \\
\hline JOP & $0.883-0.920$ & 0.947 & 0.926 \\
\hline
\end{tabular}

Table 4 shows the result of Pearson correlation analysis and descriptive statistics. The means for the variables are from 4.0 to 5.6, signifying that the levels of PHS, PSS and JOP ranging from high (4) to highest level (7). The correlation coefficients for the relationship between the independent variable (i.e., PHS and PSS) and the dependent variable (i.e., JOP) were less than 0.90 , indicating the data were not affected by serious collinearity problem (Hair et al., 2006). These results showed that the measurement scale met the acceptable standards of validity and reliability analyses.

Table 4: Pearson Correlation Analysis and Descriptive Statistics

\begin{tabular}{|l|c|c|c|c|c|}
\hline Variable & Mean & $\begin{array}{c}\text { Standard } \\
\text { Deviation }\end{array}$ & \multicolumn{3}{|c|}{ Pearson Correlation Analysis } \\
\cline { 4 - 6 } & & & 1 & 2 & 3 \\
\hline PHS & 4.0 & 1.6 & 1 & &. \\
\hline PSS & 5.2 & .90 & .11 & 1 & 1 \\
\hline JOP & 5.6 & .69 & -.13 & $.33^{* *}$ &. \\
\hline
\end{tabular}

Note: Significant at $* * p<0.01$

Fig. 1 shows the outcomes of testing PLS path model. The inclusion of PHS and PSS had explained 39 percent of the variance in JOP. The results of SmartPLS path model analysis revealed two important findings: first, PHS significantly correlated with JOP $(\beta=-0.43 ; t=3.78)$, therefore $\mathrm{H} 1$ was supported. Second, PSS significantly correlated with JOP $(\beta=0.43 ; t=6.82)$, therefore H2 was supported. In sum, this result demonstrates that occupational stress is an essential determinant of job performance in the studied organization.

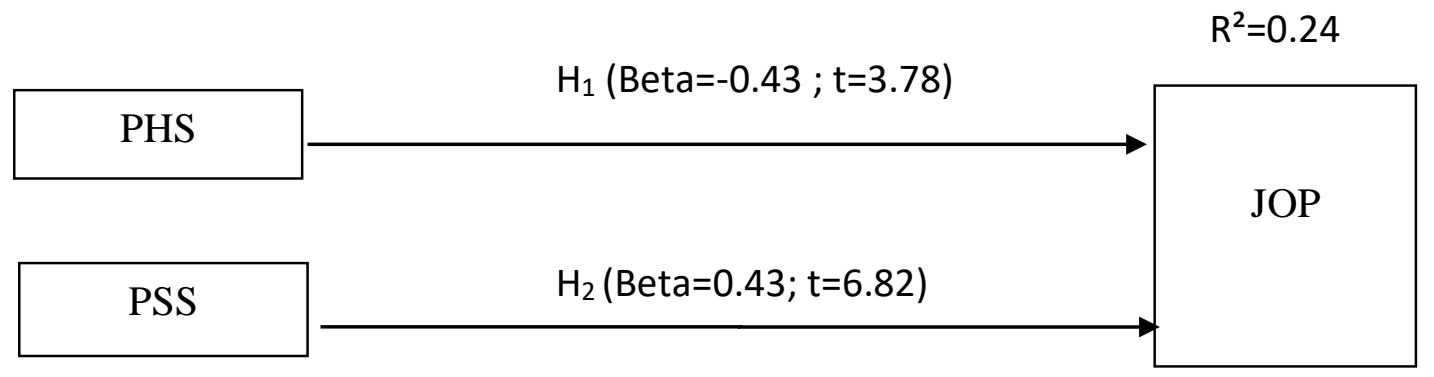

Note: Significant at $* t \geq 1.96$

Fig. 1: Outcomes of Testing PLS Path Model 
INTERNATIONAL JOURNAL OF ACADEMIC RESEARCH IN BUSINESS AND SOCIAL SCIENCES

Vol. 8, No. 6, June 2018, E-ISSN: 2222-6990 @ 2018 HRMARS

In order to determine a global fit PLS path modeling, we carried out a global fit measure (GoF) based on Wetzels et al.,(2009) guideline as follows: GoF=SQRT\{MEAN (Communality of Endogenous) $x$ $\left.\operatorname{MEAN}\left(R^{2}\right)\right\}=0.47$, indicating that it exceeds the cut-off value of 0.36 for large effect sizes of $R^{2}$. This result confirms that the PLS path model has better explaining power in comparison with the baseline values (GoF small=0.1, GoF medium=0.25, GoF large=0.36). It also provides adequate support to validate the PLS model globally (Wetzels et al., 2009).

\section{Discussion and Implications}

The findings of this study confirm that the occupational stress in humanitarian assistance does act as an important determinant of defence and security personnel job performance. In the context of this study, MDSA has planned and selected well trained defence and security personnel to carry out humanitarian assistance in order to achieve the mission of the United Nation at Middle Eastern country. According to the majority respondents, the levels of physiological stress, psychological stress, and job performance are high. This situation posits that defence and security personnel have maximized their physical and spiritual potentials to implement their duties and responsibilities according to the humanitarian assistance operating procedures, but the chaos and unpredicted conditions that exist in the country may lead to decrease their abilities in enhancing job performance.

This study provides three important implications. In terms of theoretical contribution, the results of this study confirm that physiological and psychological stresses have been important determinants of job performance in the studied organization. This result is consistent with and broadened studies by (Johnston et al., 2013; Slaski \& Cartwright, 2002; Morrison et al., 2013; Cincotta, 2005). Even though the finding of this study is significant, the effect of negative occupational stress on job performance is low. A careful observation of the semi-structured interview results shows that this finding may be affected by external factors: first, defence and security personnel who have good track records in their services are only selected in the humanitarian assistance. Second, defence and security personnel have been successfully attended preparatory training programs organized by MDSA are assigned in the humanitarian assistance. Third, the United Nation, other countries and MDSA have cooperated to provide good physical and moral support that may ease defence and security personnel executing their assignments in the humanitarian assistance. This situation may decrease the effect of negative occupational stress on job performance in the humanitarian assistance.

In regard with the robustness of research methodology, the survey questionnaires used in this study have satisfactorily met the standards of validity and reliability analyses. This may lead to the production of accurate and reliable research findings. With respect to a practical contribution, the findings of this study may be used as guidelines by practitioners to enhance the ability of defence and security personnel in managing undesirable occupational stress in organizations. The potential suggestions are: The study recommends that organizations should ensure good working environment for the personnel's and ensure that measures to minimize occupational stress such as appropriate working hours, quality tools and equipment, relative workloads, leaves and breaks are put in place. The working environment was identified as one of the biggest factors that affect personnel's performance. The defence and security personnel strongly agreed that the working environment, the level of qualification and job fitness, technical training, goals and expectations, tools and equipment, morale and organizational culture, personnel health to be affecting their performance. Defence and 
security personnel must be qualified to perform a job in order to meet expectations. The best fit for a job is identified by skills, knowledge and attitude towards the work. The findings show that good personnel's performance can be attributed to clear goals and expectations. When everyone understands the targets and expected outcomes, it is easier to take steps to get there and measure performance along the way. Under the present adverse work environments, officers and staffs should try to cultivate their personnel's work values, and their involvement in and commitment toward their organizations. The prevention and management of workplace stress requires organizational level interventions because it is the organization that creates the stress. Success in managing and preventing stress will depend on the culture in the organization. A culture of openness and understanding, rather than of criticism, is essential. If these suggestions are heavily considered this may motivate defence and security personnel to accept and perform their stakeholders' needs and expectations.

\section{Conclusion}

This study proposed a conceptual framework based on the occupational stress research literature. The results of confirmatory factor analysis confirmed that the instrument used in this study met the acceptable standards of validity and reliability analyses. The outcomes of SmartPLS path model analysis showed that physiological stress and psychological stress were significantly correlated with job performance, therefore $\mathrm{H} 1$ and $\mathrm{H} 2$ were supported. This result confirms that occupational stress does act as an important determinant of job performance in the organizational sample. This result also has supported and broadened the occupational stress studies, mostly published in Western countries. Even though the finding of this study is significant, the effect of negative occupational stress on job performance is low. A careful observation of the semi structured interview results shows that this finding may be affected by external factors that is defence and security personnel who are selected in the humanitarian assistance works have good track records in their services, obtained good exposure from the preparatory humanitarian assistance training programs, and obtained good physical and moral support from the United Nation, other countries and MDSA. These factors may decrease the effect of negative occupational stress on job performance in the humanitarian assistance. Thus, current research and practice within occupational stress model needs to consider physiological stress and psychological stress as key dimensions of the occupational stress domain. This study further suggests that the competency of personnel to appropriately plan and manage physiological and psychological stresses in carrying job will induce positive individual attitudes and behaviour (e.g., satisfaction, commitment, and quality of work life). Therefore, these positive individual outcomes may lead to maintained and support the organizational humanitarian assistance strategic mission, vision and goals.

\section{Acknowledgement}

This research works was funded by research grant, FRGS/2/2013/SS05/UPNM/02/2, National Defense University of Malaysia.

\section{Corresponding Author}

Ahmad Azan Ridzuan, Faculty of defense studies and management, National Defence University of Malaysia, Email: azan6142@yahoo.com. 
INTERNATIONAL JOURNAL OF ACADEMIC RESEARCH IN BUSINESS AND SOCIAL SCIENCES

Vol. 8, No. 6, June 2018, E-ISSN: 2222-6990 @ 2018 HRMARS

\section{References}

Abu AlRub, R. F. (2004). Job Stress, Job Performance and Social Support among Hospital Nurses. Journal of Nursing Scholarship, 36(1), 73-78.

Barclay, D., Higgins, C., \& Thompson, R. R. (1995). The Partial Least Squares (PLS) Approach to Causal Modeling: Personal Computer Adoption and Use as an Illustration. Technology Study, 2 (2), 285309.

Basowitz, H., Persky, H., Korchin, S. J., \& Grinker, R. R. (1995). Anxiety and Stress. New York: McGrawHill Book Company, Inc.

Beehr, T. A., Jex, S. M., \& Ghosh, P. (2001). The Management of Occupational Stress. In Johnson, C.M., Redmon, W.K., \& Mahwhinney, T.C. (Eds.), Handbook of Organizational Performance: Behavior Analysis and Management. New York: The Haworth Press.

Beehr A. T, Jex M.S., Stacy A. B., \& Murray A.M. (2000). Work Stressors and Coworker Support as Predictors of Individual Strain and Job Performance. Journal of Organizational Behavior, Vol. 21, No. 4, pp. 391-405.

Bohlander, G., Snell, S., \& Sherman, A. (2001). Managing Human Resources, South-Western College Publishing, Australia.

Campbell, J. P. (1990). Modeling the Performance Prediction Problem in Industrial and Organizational Psychology. In M.D. Dunnette \& L.M. Hough (Eds.), Handbook of industrial and organizational psychology, 1, 687-732, Palo Alto: Consulting Psychologists Press.

Chin, W. W. (1998). The Partial Least Squares Approach to Structural Equation Modeling. In G.A. Marcoulides (Ed.), Modern Methods for Business Research (pp. 295-358). Mahwah, NJ: Lawrence Erlbaum Associates.

Cincotta, J. A. (2005). The Link between Individual Occupational Stress and Organizational Effectiveness as shown by Performance Evaluation, Productivity Measures, and Employee Satisfaction. A Dissertation submitted to The Faculty of The Graduate School of Education and Human Development of The George Washington University.

Code, S., \& Langan-Fox, J. (2001). Motivation, Cognitions and Traits: Predicting Occupational Health, Well-Being and Performance. Stress and Health, 17, 159-74.

Coetzer, W., \& Rothmann, S. (2006). Occupational stress of employees in an insurance company. South African Journal of Business Management, 37(3), 29-39.

Colligan, T. W., \& Higgins, E. M. (2010). Workplace Stress: Etiology and Consequences. PERI Pakistan.

Corpley, M., Steptoe, A., \& Joekes, K. (1999). Job Strain and Psychiatric Morbidity. Psychological Medicine, 29, 1411-1416.

Cresswell, J. W. (1998). Qualitative Inquiry and Research Design: Choosing Among Five Traditions. London: SAGE Publications.

Davis, L.V. (1996). Role Theory and Social Work Treatment. In F.J. Turner (ed.). Social Work Treatment. Interlocking Theoretical Approaches. New York: The Free Press. pp. 581-600.

Dokotri, J. (2006). Job analysis, performance and satisfaction. Vocational Psychology Presentation. Jos: University of Jos.

Edwards, J. R. (1998). Cybernetic Theory of Stress, Coping, and Well-Being: Review and Extension to Work and Family. In Cooper, C.L. (Ed.). Theories of Organizational Stress (pp.122-52). NY: Oxford University Press.

Fornell, C., \& Larker, D. F. (1981). Structural Equation Models with Unobservable Variables and Measurement Error: Algebra and Statistics. Journal of Marketing Research, 18 (3), 328-388. 
INTERNATIONAL JOURNAL OF ACADEMIC RESEARCH IN BUSINESS AND SOCIAL SCIENCES

Vol. 8, No. 6, June 2018, E-ISSN: 2222-6990 @ 2018 HRMARS

Gachter, M., Savage, D. A. \& Torgler, B. (2011). The Relationship Between Stress, Strain and Social Capital. Policing: An International Journal of Police Strategies \& Management, 515-540.

Gefen, D., \& Straub, D. (2005). A Practical Guide to Factorial Validity Using PLS-Graph: Tutorial and Annotated Example. Communication of the Association for Information Systems, 16, 91 - 109.

Goetzel, R., Anderson, D., Whitmer, R., Ozminkowski, R., Dunn, R., \& Wasserman, J. (1998). The Relationship Between Modiwable Health Risks and Health Care Expenditures. Journal of Occupational and Environmental Medicine, 40, 843-854.

Hair, J. F., Anderson, R. E., Tatham, R. L., \& Black, W. C. (2006). Multivariate Data Analysis. New Jersey: Prentice Hall International, Inc.

Hair, J. F., Anderson, R. E., Tatham, R. L., \& Black, W. C. (2017). Multivariate Data Analysis. New Jersey: Prentice Hall International, Inc.

Henseler, J., Ringle, C. H., \& Sinkovics, R. R. (2009). The Use of Partial Least Squares Path Modeling in International Marketing. New Challenges to International Marketing Advances in International Marketing, 20, 277-319.

Hourani, L. L., Williams, T. V., \& Kress, A. M. (2006). Stress, Mental Health and Job Performance Among Active Duty Military Personnel: Findings from the 2002 Department of Deference HealthRelated Behaviors Survey. Military Medicine, 171(9), 849-856.

Hsieh, H-L., Huang, L-C., \& Su, K-J. (2004). Work Stress and Job Performance in the Hi-Tech Industry: A Closer View for Vocational Education. World Transactions on Engineering and Technology Education, 3(1), 147-150.

Ismail, A., Yao, A., Yeo, E., Lai-Kuan, K., \& Soon-Yew, J. (2010). Occupational Stress Features, Emotional Intelligence and Job Satisfaction: An Empirical Study in Private Institutions of Higher learning. Revista Negotium,16 (5) 5-33.

Ismail, A., Suh-Suh, Y., Ajis, M. N., \& Dollah, N. F. (2009). Relationship between Occupational Stress, Emotional Intelligence and Job Performance: An Empirical Study in Malaysia. Theoretical and Applied Economics, 10 (539), 3-16.

Jamal, M. (1984). Job Stress and Job Performance Controversy: An Empirical Assessment. Organizational Behavior and Human Performance, 33, 1-21.

Johnston, D., Jones, M., Charles, K., McCann, S., \& McKee, L. (2013). Stress in Nurses: Stress-Related Affect and Its Determinants Examined Over the Nursing Day. Annals of Behavioral Medicine, 45(3), 348-356.

Karasek, R., \& Theorell, T. (1990). Healthy Work: Stress, Productivity, and the Reconstruction of Working Life. New York: Basic Books.

Keshavarz, M., \& Mohammadi, R. (2011). Occupational Stress and Organizational Performance, Case Study: Iran. Procedia - Social and Behavioral Sciences, 30, 390 - 394.

Krecjcie, R. V., \& Morgan, D. W. (1970). Determining Sample Size for Research Activities. Journal of Education and Psychological Measurement, 30, 607-610.

Kwatra, S., Kaur, N., \& Raghubansi, P. (2012). Psycho-physiological Problems Among Dual Career Women: A Cause of Stress. Stud Home Com Sci, 6 (2): 71-76.

Lazarus, R. (1995). Psychological Stress in the Workplace. In R. Crandall \& P.L. Perrewe (Eds.). Occupational Stress: A Handbook. Washington DC. Taylor \& Francis. pp. 3-14.

Lazarus, R. S., \& Folkman, S. (1984). Stress, Appraisal and Coping. New York: Springer Publishing.

Leka, S., Griffiths, A., \& Cox, T. (2004). Work Organization and Stress. Nottingham: UK. World Health Organization. 
INTERNATIONAL JOURNAL OF ACADEMIC RESEARCH IN BUSINESS AND SOCIAL SCIENCES

Vol. 8, No. 6, June 2018, E-ISSN: 2222-6990 @ 2018 HRMARS

Major, C., Tobias Pietz, T., Schöndorf, E., \& Hummel, W. (2012). The Crisis Management Toolbox. From Civilian Crisis Prevention to Peacebuilding:Principles, Actors, Instruments. German Institute for International and Security Affairs (SWP) and the Center for International Peace Operations (ZIF). Germany.

Millward, L. (2005). Understanding Occupational and Organizational Psychology. Thousand Oaks, California: Sage Publications.

Morrison, K., Farquharson, B., Bell, C., Johnston, D., Jones, M., Schofield, P., Allan, J., Ricketts, I., \& Johnston, M. (2013). Nursing Stress and Patient Care: Real-Time Investigation of the Effect of Nursing Tasks and Demands on Psychological Stress, Physiological Stress, and Job Performance: Study Protocol. Journal of Advanced Nursing, 69 (10), 2327-2335.

Nabirye, R. C., Brown, K. C., Pryor, E. R., \& Maples, E. H. (2011). Occupational Stress, Job Satisfaction and Job Performance Among Hospital Nurses in Kampala, Uganda. Journal of Nursing Management, 19 (6), 760-768.

Nunally, J. C., \& Bernstein, I. H. (1994). Psychometric Theory. New York: McGraw-Hill.

Ringle, C. M., Gotz, O., Wetzels, M., \& Wilson, B. (2009). On the Use of Formative Measurement Specifications in Structural Equation Modeling: A Monte Carlo Simulation Study to Compare Covariance-based and Partial Least Squares Model Estimation Methodoligies (METEOR Research Memoranda RM/09/014). Maastricht, the Netherlands: Maastricht University.

Robbins, P. S. (2004), Organizational Behavior, Prentice Hall pub. Ed. $9^{\text {th }}$ pp. 563.

Santos, M. C., Barros, L., \& Carolino, E. (2010). Occupational Stress and Coping Resources in Physiotherapists: A Survey of Physiotherapists in Three General Hospitals. Physiotherapy, 96, 303-310.

Selye, H. (1964). From Dream to Discovery, NY:McGraw-Hill.

Selye, H. (1987). Stress Without Distress, London: Transworld.

Sekaran, U., \& Bougie, R. (2011). Research Methods for Business: A Skill Building Approach. United Kingdom: John Wiley \& Sons, Ltd.

Slaski, M., \& Cartwright, S. (2002). Health, Performance and El: An Exploratory Study of Retail Managers. Stress and Health, 18(2), 63- 68.

Slaski, M., \& Cartwright, S. (2003). El Training and Its Implications for Stress, Health and Performance. Stress and Health, 19(4), 233-239.

Ugoji, E. I. (2003). Managing Administrative Stress in Educational Institutions: (A Study of Selected Nigerian Universities). Journal of Niger Delta Research (JONDR), 5(1), 90-99.

Ugoji, E. I., \& Isele, G. (2009). Stress Management \& Corporate Governance in Nigerian Organizations. European Journal of Scientific Research, 27(3), 472-478.

UN (2008). The United Nations Today. The Department of Public Information. asdf, United Nations New York.

Wetzels, M., Odekerken-Schroder, G., \& Van Oppen, C. (2009). Using PLS Path Modeling for Assessing Hierarchical Construct Models: Guidelines and Empirical Illustration. MIS Quarterly, 33 (1), 177195.

World Health Organization (WHO) (2005). Mental Health and Working Life. WHO European Ministerial Conference on Mental Health: Facing the Challenges, Building Solutions. Retrieved June 19, 2007, from www.euro.who.int/document/mnh/ebrief06.pdf, .

Yu-Fei (Melissa), C., Ismail, A., Ahmad, R., \& Kuek, T. Y. (2012). Impacts of Job Stress Characteristics on the Workforce - Organizational Social Support as the Moderator. South-Asia Journal of Marketing and Management Research, 2(3), 1-20. 